\title{
Microstructure-mediated Optical Effects in Southern African Snakes
}

\author{
Ishan Singh ${ }^{1, *}$, and Graham Alexander ${ }^{1}$ \\ ${ }^{1}$ School of Animal, Plant, and Environmental Sciences, University of Witwatersrand, P.O. Wits, 2050, South Africa
}

\begin{abstract}
The scales of the African Viper Bitis arietans were tested for optical effects. Spectral intensity was recorded at incident angles over the visible spectrum for dark, pale, and ventral scale regions. The lowest spectral intensity recordings were associated with scales which have the greatest level of microstructuring. Our results indicate that scale appearance in B. arietans is a product of microstructure-mediated optical effects. The optical effect may play a role in improving the ecological performance of the snake in its natural environment.
\end{abstract}

\section{Introduction}

Some species of snake have microstructures called 'microornamentation' on their scales [1]. The spatial arrangement of microornamentation determines the optical properties of the scale, typically its reflectance. Optical effects such as structural colour are produced through the interaction of electromagnetic radiation with microornamentation [2]. The resulting light reflected off an animal's integument determines the animal's visual appearance [3] and thus impacts its ecological relationships. This study aims to investigate if microornamentation creates optical effects in the scales of $B$. arietans.

\section{Methods and Materials}

Shed skin from a $B$. arietans was collected from the National Zoological Gardens (Pretoria, Reference: NZG/RES/P/001/F/02 P15/03. Reference: 17-04-2015O). We sampled scales from five areas along the length of the body of each specimen. Scale colour was recognised using spectrophotometry.

For microscopy, samples sputter coated with \pm 10 $\mathrm{nm}$ of Carbon and $\pm 5 \mathrm{~nm}$ Chromium were observed at an accelerating voltage of $30.00 \mathrm{kV}$ using a FEI Nova 600 Nanolab FIB/ SEM (FEI, Munich, Germany). The mean height and mean density of microstructures were calculated for 10 structures per sample and for five

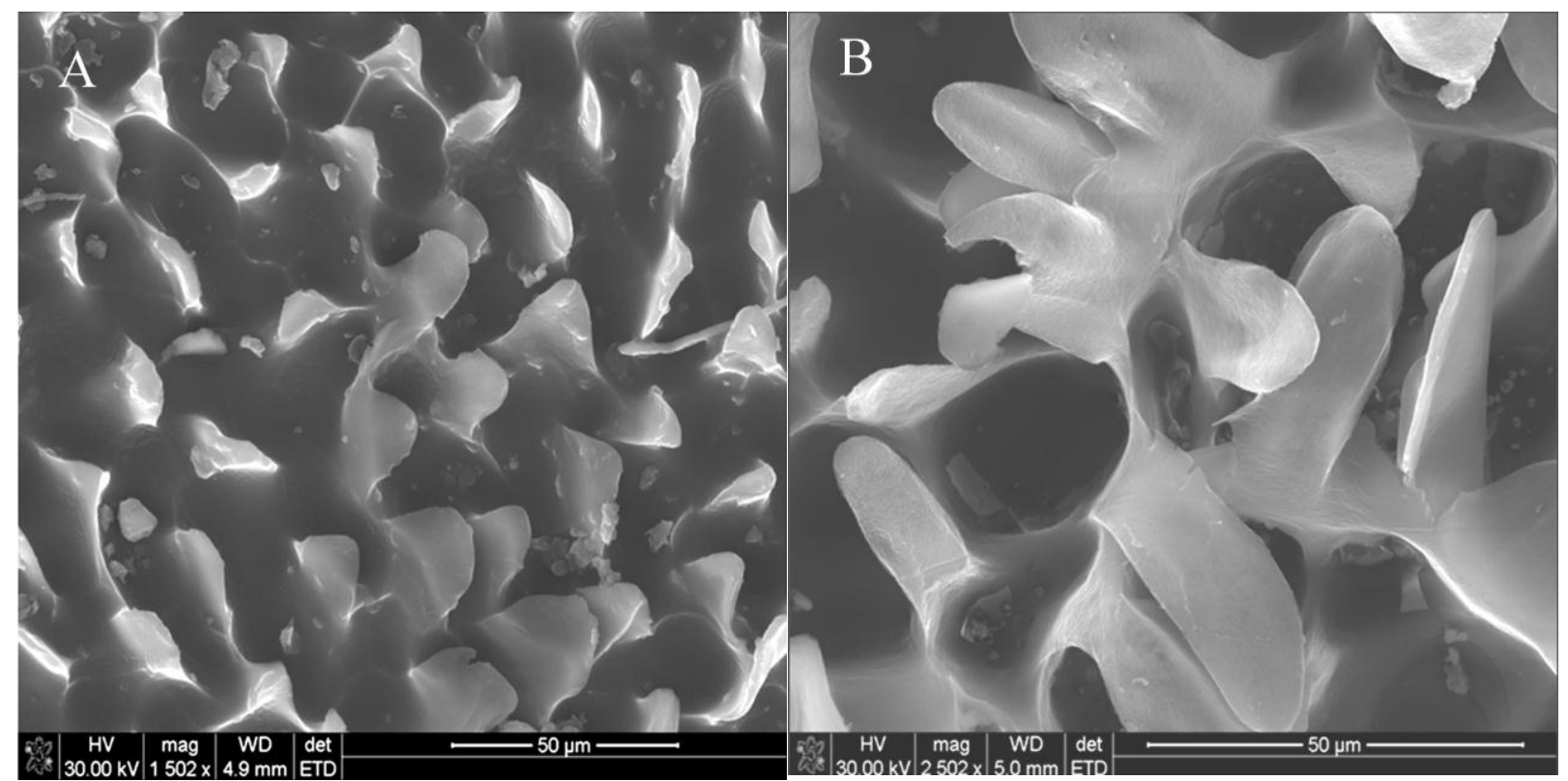

Figure 1. Electron micrographs of pale (A) and dark (B) scale regions of $B$. arietans showing microstructures on the scale surface. Scale bars: 50 um

Corresponding author: ishp2singh@gmail.com

C The Authors, published by EDP Sciences. This is an open access article distributed under the terms of the Creative Commons Attribution License 4.0 (http://creativecommons.org/licenses/by/4.0/). 


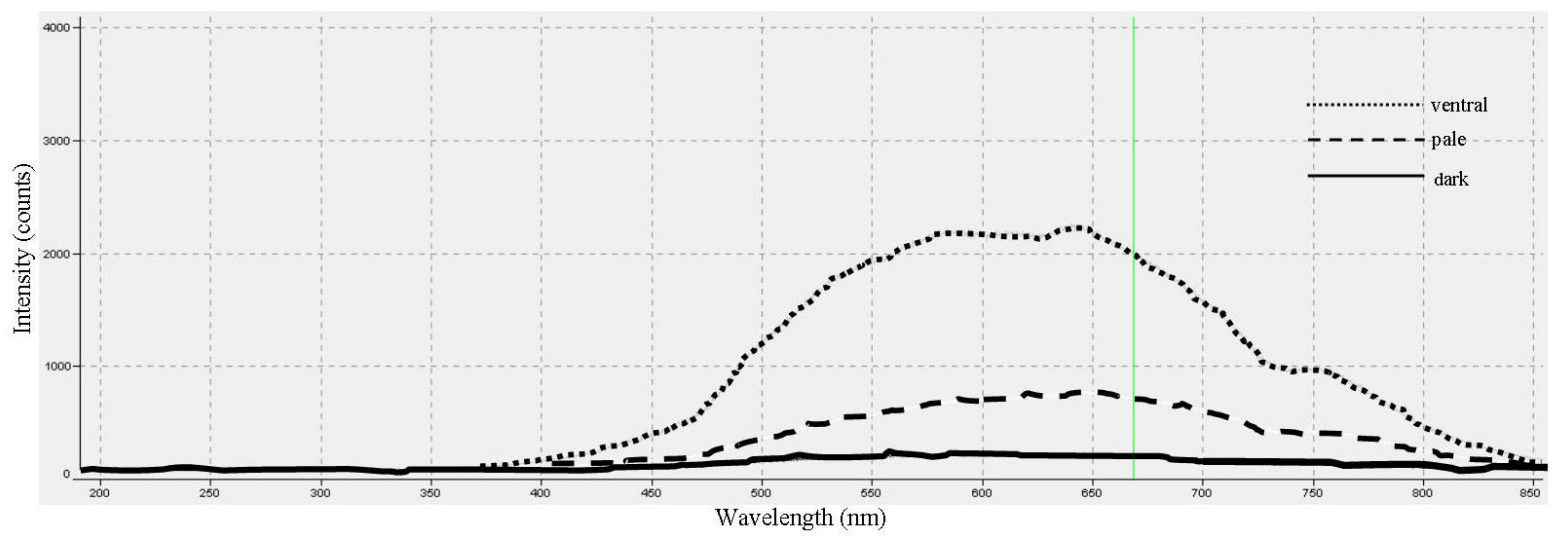

Figure 2. Spectra recorded for pale, dark, and ventral scales at incident angles over the visible spectrum.

samples per individual. Structure density per sample was counted using a haemocytometer in five $100 \mathrm{~mm} \times 100$ mm quadrats.

To measure optical effects, twenty $1 \mathrm{~cm}^{2}$ pieces of skin were excised from exuviam. Of these, 10 samples were sputter-coated with $15 \mathrm{~nm}$ Gold-Palladium to control for pigmentary differences, and 10 samples were left uncoated. We took spectral readings (Ocean Optics Inc, Dunedin, Florida, USA) in triplicate over the visible spectrum at incident angles.

\section{Results}

Microstructures were observed on the surface of both dark and pale scales (fig. 1), but not ventral (belly) scales. A morphometric analysis indicated that the density of microstructures on dark scales (mean density $=2696 \pm 613 \mathrm{~mm}^{-2}$ ) and pale scales (mean density = $\left.2640 \pm 497 \mathrm{~mm}^{-2}\right)$ did not differ significantly $\left(\mathrm{t}_{8,0.8}=0.26\right.$; $\mathrm{p}=0.80)$. There is a significant difference in height of microornamentation (Mann-Whitney U-statistic = 184.00; $\mathrm{p}<0.0001$ ) between dark (mean height $=40.83 \pm$ $8.33 \mu \mathrm{m})$ and pale (mean height $=17.29 \pm 4.05 \mu \mathrm{m})$ scale regions.

The recorded spectra of dark, pale, and ventral regions differed greatly (fig. 2). Dark regions had the lowest recorded intensity of all, while both dark and pale regions were lower than the ventral regions. Ventral scales, due to their lack of microstructures, were used as a control.

\section{Conclusion}

Our results show that colour differences correspond to the height of scale microstructure. We conclude that scale colour in B. arietans is a product of optical effects created by microornamentation. Bitis arietans is widely distributed across Africa [4], and as an ambush forager may remain in ambush positions for extensive periods of time. Thus, there is great reliance on visual and chemical camouflage to avoid detection by predators and prey [5]. We suggest that the optical effects created by microornamentation contribute to the snake's visual camouflage, and thus has an important function in the ecology of this species.

The authors wish to acknowledge the National Research Foundation, the National Zoological Gardens, and The University of Witwatersrand, South Africa.

\section{References}

1. M. Spinner, A. Kovalev, S. Gorb, G. Westhoff. Nature 3 (2013)

2. P. Vukusic. Ophthalmic Physiol Opt 30 (2010)

3. P. Vukusic, D. Stavenga. J. R. Soc. Interface 6 (2009)

4. G.J. Alexander, J. Marais. A guide to the reptiles of southern Africa (Struik Nature, Cape Town 2007)

5. A.K. Miller, B. Maritz, S. McKay, X. Glaudas, G.J. Alexander. Proc. R. Soc. B 282 (2015) 